\title{
AS INSTITUIÇÕES MUSEOLÓGICAS E AS PRÁTICAS DE LAZER ${ }^{1}$
}

Recebido em: 22/01/2018

Aceito em: 28/09/2018

\author{
Evaldo Pereira Portela ${ }^{2}$ \\ Cristiane Miryam Drumond de Brito ${ }^{3}$ \\ Claudia Franco Monteiro ${ }^{4}$ \\ Universidade Federal de Minas Gerais \\ Belo Horizonte - MG - Brasil
}

\begin{abstract}
RESUMO: Este estudo pretende discutir a prática de lazer em museus compreendendo que a indústria do lazer tem ampliado e transformado a relação do público com os museus e conseguido imprimir nesse espaço um local de realização de práticas de lazer e atração turística. A partir da concepção da Nova Museologia, visa apresentar políticas que vêm sendo implementadas no Brasil e em outros países com a proposta de um novo museu que faça brotar um sentimento de pertencimento pela população, e ainda, tenham propostas comprometidas com o lazer, trazendo formas mais atrativas de interação para os visitantes. Frente a isso, é importante compreender se de fato os museus adotam práticas de lazer e se essas práticas possibilitam processos de inclusão social. Este trabalho teve como prerrogativa conhecer a produção cientifica em formato de artigos no período de 2011 a 2015 em que foram utilizados os descritores em inglês "museum and leisure". Após seleção dos artigos pelos critérios de inclusão, chegou-se a três categorias de análise que formaram o objeto de estudo deste trabalho, sendo elas: a) Nova museologia; b) Lazer em museus e c) Marketing em museus. Constatou-se que há poucos trabalhos no âmbito internacional que tratam o binômio museu-lazer nas bases de dados de periódicos eletrônicos utilizados e que não houve nenhum trabalho realizado por pesquisador brasileiro. É chamada atenção para a necessidade de maiores pesquisas sobre a relação museu e lazer no intuito de subsidiar ações para construção de políticas públicas de democratização dos espaços museológicos, no sentido de promover ações de inclusão social, para questões de gênero e de atração às pessoas de menor nível de escolaridade. Faz-se uma crítica de que os museus ainda são espaços para classes mais privilegiada sendo esta uma imagem a ser desconstruída.
\end{abstract}

PALAVRAS CHAVE: Atividades de Lazer. Museus. Marketing. Inclusão Social.

\footnotetext{
${ }^{1}$ Este artigo é fruto de uma dissertação na linha de pesquisa Lazer e Sociedade, do Programa de Pósgraduação Interdisciplinar em Estudos do Lazer da Universidade Federal de Minas Gerais (UFMG). O vínculo com essa linha de pesquisa justifica-se pela pesquisa conter temas que tratam de cultura, políticas públicas e comunicação como prática de lazer.

${ }_{2}^{2}$ Mestre em Estudos do Lazer, Graduado em Museologia e Licenciado em História; Diretor do Museu Solar Monjardim/IBRAM/MinC.

${ }^{3}$ Docente do Departamento de Terapia Ocupacional e do Programa de Pós-graduação Interdisciplinar em Estudos do Lazer da Universidade Federal de Minas Gerais (UFMG).

${ }^{4}$ Docente do Departamento de Terapia Ocupacional da UFTM e Doutoranda do Programa de Pósgraduação Interdisciplinar em Estudos do Lazer da Universidade Federal de Minas Gerais (UFMG).
} 


\section{MUSEOLOGICAL INSTITUTIONS AND LEISURE PRACTICES}

ABSTRACT: This study intends to discuss the leisure practice in museums, understanding that the leisure industry has expanded and transformed the relationship between the public and museums and managed to print in this space a place for the practice of leisure and tourist attraction. From the conception of the New Museology, it aims to present policies that have been implemented in Brazil and in other countries with the proposal of a new museum that gives rise to a sense of belonging for the population, and also, have proposals committed with leisure, bringing forms more engaging interaction for visitors. Faced with this, it is important to understand whether museums actually adopt leisure practices and whether these practices enable processes of social inclusion. This work had as interest to know the scientific production in format of articles in the period of 2011 to 2015 in which the English descriptors "museum and leisure" were used. After selection of the articles by the inclusion criteria, three categories of analysis formed the object of study of this work, being: a) New museology; b) Leisure in museums and c) Marketing in museums. It was verified that there are few works in the international scope that treat the binomial museum-leisure in the databases of electronic journals used and that there was no work done by Brazilian researcher. Attention is drawn to the need for further research on the museum and leisure relationship in order to subsidize actions for the construction of public policies for the democratization of museological spaces, in order to promote social inclusion actions, for gender issues and attraction to the people of lower level of schooling. It is criticized that museums are still spaces for more privileged classes and this is an image to be deconstructed.

KEYWORDS: Leisure Activities. Museums. Marketing. Social Inclusion.

\section{Introdução}

Os museus ainda são marcados pela ideia de local ultrapassado, velho, distante da sociedade (NASCIMENTO, 1998). Essa marca tem relação histórico-cultural, uma vez que a proposta era servir como repositório de objetos destinados à apreciação de poucos. Desde a idade média, o museu guardava objetos doados a igreja como obras de arte pelo desprendimento dos fiéis a seus bens materiais. No Renascimento europeu surgiram os gabinetes de curiosidades que abrigavam coleções, curiosidades. $\mathrm{O}$ museu sempre foi uma instituição aristocrática, herdeira dos gabinetes de curiosidades dos príncipes, das catedrais e mosteiros (VARINE, 2012). A Revolução Francesa traz a concepção do museu como espaço destinado a coletar, gerir e disseminar informações 
por intermédio da cultura material. Essa produção do museu não é desprovida de questões ideológicas. O museu, portanto, sempre foi considerado um lugar sacralizado que consagra a ordem social (CONAL, 2013), um local para pessoas elitizadas e educadas em um contexto sociocultural distante das camadas populares.

Na década de 60, período de muitas mudanças no mundo ocidental, tanto a nível político quanto cultural. Vários movimentos sociais clamavam mudanças e o museu não ficou de fora das reinvindicações. Houve questionamentos do papel do museu e foi denunciado como templos que armazenavam e sacralizavam valores burgueses. Neste movimento surgiu o que se denomina Nova Museologia, que busca uma efetiva mudança social do museu e visa brotar o sentimento de pertencimento aos museus. Preconizam que os museus sejam apropriados pelas pessoas, incluindo práticas de lazer.

Atualmente, os museus em diversas cidades do mundo vêm se transformando em pontos de opção de lazer, principalmente para classe média e média alta, ainda não é um espaço de circulação das classes populares. Assim a indústria de lazer vem investindo neste espaço, dando a ele um aspecto dinâmico, interativo e turístico.

Outras manifestações ocorrem por meio de reinvindicações sociais para que sejam implementadas políticas públicas, tanto no Brasil quanto em outros países de potencializar os museus como espaço de construção de conhecimento, expressão democrática das diversas classes sociais e com propostas comprometidas com o lazer e com a inserção de camadas populares da população. No Brasil, por exemplo, a prática de lazer nos museus como ação inerente dessas instituições e como parte das políticas sociais de inclusão é uma prerrogativa prevista em Lei e nos processos históricos culturais dos museus e da museologia. No ano de 2009 foi um marco para o setor 
museológico em nosso país, pois, dando continuidade à Política Nacional de Museus, em 14 de janeiro foi decretada e sancionada a Lei $\mathrm{n}^{\mathrm{o}} 11.904$ que institui o Estatuto de Museus. Neste mesmo ano foi decretada e sancionada a Lei $\mathrm{n}^{\mathrm{o}} 11.906$ que cria $\mathrm{o}$ Instituto Brasileiro de Museus (IBRAM). Essa nova autarquia vinculada ao Ministério da Cultura foi a única criada nos dois mandatos do presidente Luiz Inácio Lula da Silva. O órgão é responsável pela aplicação da Política Nacional de Museus e pela melhoria dos serviços do setor, tais como, aumento de visitação e arrecadação dos museus, fomento de políticas de aquisição e preservação de acervos e criação de ações integradas entre os museus brasileiros. Com isso, a Política Nacional de Museus colocou o Brasil no pequeno grupo de países que possuem uma política pública voltada para o desenvolvimento museal. Frente a isso, é importante compreender se, de fato, os museus adotam práticas de lazer e se essas práticas possibilitam processos de inclusão social.

O lazer no mundo ocidental é discutido quase sempre sobre duas teorias. Conforme Gomes (2011), a primeira fala das influências greco-romanas da Antiguidade que marcaram a constituição do mundo ocidental. Influências essas ocorridas no campo da política, artes, arquitetura, filosofia entre outras. A segunda refere-se aos processos que definiram a ocorrência da modernidade, como a industrialização e a urbanização, ou seja, processos que marcaram a transição da antiga ordem feudal ao capitalismo moderno. Aqui, adotamos uma terceira via que é o lazer como "uma necessidade humana e dimensão da cultura que constitui um campo de práticas sociais vivenciadas ludicamente pelos sujeitos, estando presente na vida 
cotidiana em todos os tempos, lugares e contextos" (GOMES ${ }^{5}, 2011$ apud GOMES, 2014, p. 9).

Portanto, buscamos refletir sobre a correlação do museu com o lazer nesta perspectiva da necessidade humana e inserção cultural. Verificarmos em produções científicas quais tem sido os propósitos do lazer em museus.

\section{Metodologia}

Este trabalho teve como prerrogativa conhecer a produção cientifica em formato de artigos indexados no período de 2011 a 2015, sobre museu e lazer. Foram utilizados os descritores em inglês "museum and leisure". A pesquisa dos artigos foi realizada nas seguintes bases de dados: SCIELO (Scientific Eletronic Library Online), LILACS (Literatura Latino-americana e do Caribe em Ciências da Saúde), SCOPUS (produção de pesquisa do mundo nas áreas de ciência, tecnologia, medicina, ciências sociais, artes e humanidades) e WEB OF SCIENCE (é um conjunto de bases de dados com indexação em ciências, ciências sociais, artes, humanidades). Optou-se por utilizar descritores em inglês e dentre os critérios de inclusão deveriam conter as palavras museum e leisure no título ou palavras chave. Partiu-se da ideia de que a pesquisa na língua inglesa não excluiria os artigos em português, pois os mesmos possuem descritores, resumo e título na língua inglesa. Após seleção dos artigos pelos critérios de inclusão, foram lidos exaustivamente e chegou-se a três categorias de análise que formaram o objeto de estudo deste trabalho, sendo elas: a) Nova museologia; b) Lazer em museus e c) Marketing em museus. Nesse processo foi encontrado um único artigo em português,

5 GOMES, Christianne. Mapeamento Histórico do Lazer na América Latina: Em busca de novas abordagens para os estudos sobre o tema. In: ISAYAMA, Hélder Ferreira; SILVA, Sílvio Ricardo da (Org.). Estudos do lazer: um panorama. Rio de Janeiro: Apicuri, p. 145-164, 2011. 
mas excluído do estudo por tratar de uma relação terapêutica ocupacional com a população idosa em um museu de arte. Analisaram-se então os artigos encontrados na língua inglesa.

\section{Resultados e Discussão}

A primeira etapa da revisão bibliográfica consistiu em uma busca de artigos utilizando os descritores Museum e Leisure resultando em um total de 270 artigos. Em seguida, uma nova busca delimitou o período compreendido entre os anos 2011 a 2015, resultando em 94 artigos. A partir da leitura de todos os títulos e palavras chave dos artigos foram selecionados aqueles que incluíam as palavras Museum e Leisure no título ou descritores, o que resultou em 22 artigos selecionados para leitura do resumo, e por fim, após leitura dos resumos 9 artigos contemplaram a proposta da pesquisa e foram selecionados para serem lidos na integra. Porém, apenas 1 artigo não foi disponibilizado gratuitamente restando 8 artigos para análise. Após seleção e leitura dos artigos, chegou-se a três categorias de análise que formaram o objeto de estudo deste trabalho, sendo elas: a) Nova museologia; b) Lazer em museus e c) Marketing em museus.

Apresentamos no Quadro abaixo os artigos selecionados para a revisão: 


\section{ARTIGOS SELECIONADOS}

\begin{tabular}{|c|c|c|c|c|}
\hline Ano & Autor(es) & Nome do artigo & Objetivos & Tema tratado \\
\hline 2011 & $\begin{array}{l}\text { Roberson, Donald N., } \\
\text { Jr. }\end{array}$ & $\begin{array}{l}\text { Free Time in an Art Museum: } \\
\text { Pausing, Gazing and } \\
\text { Interacting }\end{array}$ & $\begin{array}{c}\text { Compreender melhor as qualidades e natureza } \\
\text { do indivíduo em suas experiências em visita } \\
\text { aos museus de arte e estimular a reflexão } \\
\text { sobre a natureza do lazer em notáveis sítios } \\
\text { culturais. }\end{array}$ & $\begin{array}{l}\text { Lazer em museu de } \\
\text { arte. }\end{array}$ \\
\hline 2011 & $\begin{array}{l}\text { Davidson, Lee; Sibley, } \\
\text { Pamela }\end{array}$ & $\begin{array}{l}\text { Audiences at the "New" } \\
\text { Museum: Visitor } \\
\text { Commitment, Diversity and } \\
\text { Leisure at the Museum of } \\
\text { New Zealand Te Papa } \\
\text { Tongarewa }\end{array}$ & $\begin{array}{l}\text { Mostrar o atual reposicionamento dos museus } \\
\text { na indústria do lazer e do turismo sob a ótica } \\
\text { da nova museologia. }\end{array}$ & $\begin{array}{l}\text { Nova museologia e } \\
\text { indústria do lazer. }\end{array}$ \\
\hline 2011 & Miller, Kathleen J. & $\begin{array}{l}\text { Inclusive marketing in the } \\
\text { constructivist museum: A } \\
\text { study of non-visitors' needs }\end{array}$ & $\begin{array}{l}\text { Analisar as práticas de marketing adotadas } \\
\text { para atrair maior número de visitantes ao } \\
\text { Museu de Arte Figge em Davenport, Iowa } \\
\text { E.U.A., objeto de estudo da pesquisa. }\end{array}$ & Marketing em museu. \\
\hline 2012 & $\begin{array}{l}\text { Schaller, Richard; } \\
\text { Harvey, Morgan; } \\
\text { Elsweiler, David }\end{array}$ & $\begin{array}{l}\text { Out and about on museums } \\
\text { night: Investigating mobile } \\
\text { search behaviour for leisure } \\
\text { events }\end{array}$ & $\begin{array}{c}\text { Investigar como as pessoas se comportam e } \\
\text { buscam numa pesquisa on-line de lazer } \\
\text { cultural. }\end{array}$ & $\begin{array}{l}\text { Lazer em museu on- } \\
\text { line. }\end{array}$ \\
\hline 2013 & Skov, Mette & $\begin{array}{l}\text { Hobby-related information- } \\
\text { seeking behaviour of highly } \\
\text { dedicated online museum } \\
\text { visitors }\end{array}$ & $\begin{array}{c}\text { Mostrar que hoje se busca lazer por } \\
\text { ferramentas on-line e explorar as } \\
\text { características dos visitantes de museu on- } \\
\text { line. }\end{array}$ & $\begin{array}{l}\text { Lazer em museu on- } \\
\text { line }\end{array}$ \\
\hline 2014 & Yang, Jing & $\begin{array}{l}\text { The art and culture } \\
\text { companions: Art museum } \\
\text { volunteering as serious } \\
\text { leisure in Finland }\end{array}$ & $\begin{array}{l}\text { Explorar o envolvimento de voluntários em } \\
\text { um museu de arte e como essa ação beneficia } \\
\text { os envolvidos como forma de lazer. }\end{array}$ & $\begin{array}{l}\text { Lazer em museu de } \\
\text { arte. }\end{array}$ \\
\hline 2015 & $\begin{array}{l}\text { Brown, Jennifer L.; } \\
\text { MacDonald, Ronald; } \\
\text { Mitchell, Richard }\end{array}$ & $\begin{array}{c}\text { Are People Who Participate } \\
\text { in Cultural Activities More } \\
\text { Satisfied with Life? }\end{array}$ & $\begin{array}{c}\text { Saber se as pessoas que participam de } \\
\text { atividades de lazer cultural têm a satisfação } \\
\text { de vida maior do que as pessoas que não } \\
\text { fazem, se diferentes tipos de lazer têm a } \\
\text { mesma influência sobre a satisfação com a } \\
\text { vida e se a satisfação depende da frequência } \\
\text { de participação ou o número de atividades } \\
\text { realizadas. }\end{array}$ & $\begin{array}{l}\text { Lazer cultural como } \\
\text { melhoria na qualidade } \\
\text { de vida. }\end{array}$ \\
\hline 2015 & Garner, Betsie & $\begin{array}{l}\text { Mundane Mommies and } \\
\text { Doting Daddies: Gendered } \\
\text { Parenting and Family } \\
\text { Museum Visits }\end{array}$ & $\begin{array}{l}\text { Mostrar a diferenciação de gênero em } \\
\text { visitação de famílias em museu. }\end{array}$ & $\begin{array}{l}\text { Lazer em família em } \\
\text { visita a museu. }\end{array}$ \\
\hline
\end{tabular}

Quadro 1: Artigos selecionados para a pesquisa. 


\section{A Nova Museologia}

O termo Nova Museologia nasce no início dos anos 1980, porém, é no Canadá, em 1984, com a Declaração de Quebec, evento promovido pelo Conselho Internacional de Museus - ICOM, que as definições norteadoras para a Nova Museologia são elaboradas. Destaca-se a função social do museu integrando a população em suas ações (DUARTE, 2013).

Os museus estão procurando atender as exigências externas, do público visitante, tais como: acessibilidade e as aspirações por mais educação não formal (ROBERSON, 2011). Práticas inclusivas são encontradas dentro dos museus, o que é compreendido como sendo museus construtivistas por alguns autores (MILLER, 2011). Esses museus construtivistas se caracterizam por considerar os conhecimentos e experiências anteriores dos visitantes no contexto de uma exposição museológica, o que dá oportunidade para o mesmo construir seu próprio significado e formar o seu próprio entendimento. $\mathrm{O}$ visitante deve ser um participante ativo e, inevitavelmente, ser capaz de fazer sentido a exposição, a apresentação ou a experiência de aprendizagem em que irá ocorrer (MILLER, 2011). As experiências humanas estão cada vez mais presentes no espaço musealizado, o que transforma o sentido do museu, antes orientados para o objeto e agora voltado para a sociedade, nominado por alguns de "museu social" (SOARES, 2008).

Os novos museus se adaptam a realidade atual, aplicam o uso de tecnologias para tornar as áreas expositivas mais acessíveis, bem como a presença de educadores e agentes comunitários. 
Alguns, por exemplo, têm se voltado para o uso da internet a fim de permitir o acesso mais amplo e também maior proteção das coleções (ROBERSON, 2011). O uso da internet e de novas tecnologias como o museu online são também formas de interação construídas na atualidade.

O fator interacional é algo preconizado pela Nova Museologia, como por exemplo, os museus direcionados às crianças, onde ocorrem atividades que promovem a interação entre elas e seus familiares. Possibilita vivências com jogos que estimulam a imaginação e experiências corporais, emocionais e cognitivas por meio da arte, ciência e cultura baseada em fatos históricos, entre outros. Em quatro museus foi realizada uma pesquisa sobre a relação da criança e a família neste ambiente. Observou-se que as crianças eram tocadas pelo jogo, interagiram com uma ampla variedade de materiais ligados a conceitos educacionais específicos. Crianças escavavam camadas de areia procurando fósseis no museu de ciências naturais no Academy of Natural Science's Big Dig, conversavam com atores da Revolução Americana no American Revolutionists at Independence National Historic Park e se relacionavam com eles como se vivessem no século XVIII da Philadelphia. A interação e ludicidade é algo bem presente nos museus que se propõe a receber crianças (GARNER, 2015). Também ocorre essa interação em museus em que há frequentadores adultos, o apelo a jogos e o trabalho com emoções são relatados por seus visitantes (GARNER, 2015; ROBERSON, 2011).

Outro aspecto dessa nova museologia é a extensão do museu integrado a comunidade, uma espécie de serviço social com base na arte e na cultura. São ofertados serviços culturais e de arte a grupos marginalizados, ou seja, não é o deslocamento de pessoas ao museu, mas é o museu indo ao encontro destes grupos através dos voluntários. A arte funciona como catalisador nas relações interpessoais, fomentando novos espaços sociais e quebrando barreiras de comunicação. Essa iniciativa gera 
oportunidades de compartilhamento de problemas, as pessoas são tocadas e se encorajam em falar de sentimentos profundos (YANG, 2014).

O museu também se estende às visitações on-line, por isso há uma tendência em ter coleções amplamente acessíveis através da digitalização desse património cultural para a Internet. Visitas on-line em sites de museus tornaram-se populares e alguns museus relatam que o número de visitantes do museu on-line excede o número de visitantes do museu físico (SKOV, 2013).

A nova museologia descrita e analisada nos artigos não perde de vista o caráter do museu de conservar bens e valores culturais e acrescenta dinâmicas na qual os participantes adquiram saúde cultural, engajamento, autoestima, solidariedade, de forma prazerosa, lúdica e interativa (COSTA, 2012).

A implicação dos visitantes no museu, com elementos que trabalhem a emoção e as sensações, traz a potencialidade destas serem relacionadas à memória, melhor dito, podem trazer lembranças, sentimentos, imaginação. A memória e a emoção estão completamente imbricadas uma na outra e tem relação com a ideia do museu de guardar memória.

Na verdade a Nova Museologia aproxima o museu das pessoas e essas são capazes de construir e reconstruir memórias. Portanto, a memória nessa Nova Museologia não é trabalhada de forma estática, ela é dinâmica, e envolve o visitante de tal modo que o museu deixa de ser um templo sacralizado e passa a ganhar um espaço mais significativo em suas vidas.

A Nova Museologia também traz desafios em lidar com recursos, financeiros competitivos e reduzidos, e ao mesmo tempo, manter um grande número de visitação por meio de ofertas que respondam as expectativas dos visitantes. Uma eficiente estratégia para contemplar essa necessidade foi lançada por dois pesquisadores da Nova 
Zelândia, em um estudo realizado a partir da análise do banco de dados referente a mais de uma década de visitação no Museu New Zealand Te Papa Tongarewa inaugurado em 1998. Reconhecido por manter alta visitação dada as diversas atividades agregadas ao espaço museológico, como funções de lazer relativas aos feriados, eventos sociais e eventos especiais. Essa pesquisa concluiu que o Museu em questão se configura na ideia da Nova Museologia quando atende a uma população multicultural e busca se renovar reposicionando-se dentro das atuais exigências do mercado de lazer. Entende-se a partir disso o grande desafio a ser enfrentando pelos museus em geral na concepção da Nova Museologia: a de oferecer um espaço democratizado e que dê voz a grupos sociais desfavorecidos e simultaneamente, cresça dentro de um modelo de gestão empresarial independente compreendendo os museus como parte do lazer e do turismo industrializado (SMITH ${ }^{6}, 2006$ apud DAVIDSON; SIBLEY, 2011).

\section{Lazer em Museus}

Os museus, diante de todo o conjunto de tipologias, existentes até o momento, buscam acompanhar as transformações sociais, políticas e econômicas que ocorrem no mundo. Observar as várias formas possíveis de lazer neste contexto resultaria em vasto material a ser analisado por muitos trabalhos acadêmicos. Frente a essa complexidade que envolve lazer em museus, propor o estudo de ações recentes atende o objetivo desta pesquisa. Além disso, segundo Miller (2011), há muitos estudos sobre visitantes, mas poucos dirigidos ao lazer ou estudos sobre as necessidades dos chamados não visitantes, ou seja, das pessoas que não tem o hábito de ir ao museu. Essa autora aponta a importância em saber dessas necessidades para assim serem atraídas aos museus e as define como atividades desejadas pelas pessoas no seu tempo disponível fora do

\footnotetext{
${ }^{6}$ SMITH, L. Uses of heritage. London, UK and New York, NY: Routledge, 2006.
} 
trabalho ou compromisso. Os autores Davidson e Sibley demonstram essa preocupação, quando ao estudar a razão da visitação ou não visitação ao museu, mencionam uma pesquisa psicográfica que indica a diferença de valores que ambos depositam nesse tipo de lazer. Pessoas que frequentam os museus não menos que três vezes ao ano, são pessoas que valorizam a aprendizagem, desafios e oportunidades em seu tempo de lazer. Pessoas que não tem o hábito de visitar museus, geralmente dão maior valor a interações sociais, participação ativa em ambientes confortáveis e familiares. Visitantes ocasionais, com máximo de visita ao museu uma ou duas vezes ao ano, apresentam interesse similar ao não visitante, tendendo a fazer visitas em ocasiões especiais, eventos importantes e de atividades familiares. (HOOD 'S, 19937 , 2004 ${ }^{8}$ apud DAVIDSON; SIBLEY, 2011).

Essas informações descrevem as razões do comprometimento dos visitantes e qual lugar o museu e o turismo ocupam em suas vidas. Ao pensarmos o museu, basicamente, como um espaço democrático, apresentado em várias tipologias e de característica informacional, somos levados naturalmente a associá-los ao lazer. São lugares onde as pessoas escolhem para passar o tempo livre e situações casuais de lazer (SCHALLER; HARVEY; ELSWEILER, 2012; DAVIDSON; SIBLEY, 2011). Segundo Roberson (2011), em uma cidade há três lugares onde a aprendizagem baseada em lazer como um hobby pode efetivamente ocorrer: casa, bibliotecas e museus. Estes ambientes são diferenciados, por que em casa esse lazer em geral pode ser perturbado pelo movimento cotidiano da casa, com a presença de animais de estimação, com diálogo entre familiares, a televisão e, internet entre outros. As bibliotecas e museus são espaços que proporcionam uma maior concentração no uso do lazer.

\footnotetext{
${ }^{7}$ HOOD, M. After 70 years of audience research, what have we learned? Who comes to museums, who does not, and why? Visitor Studies, 5, p. 77-87, 1993.
} 
Especificamente o museu Te Papa Tongarewa, na Nova Zelândia, tem diversas maneiras de funcionar como um local de lazer. Foi observado picos de visitação, com sucesso de público em exposições temporárias, por exemplo, associadas ao Senhor dos Anéis. Essa exposição contou com adereços da trilogia e alcançou 325.000 (trezentos e vinte e cinco mil) visitantes ao longo de dois anos de exposição. Outra exposição mais visitada foi de Monet e os impressionistas com 152.094 (cento e cinquenta e dois mil e noventa e quatro) visitantes em um ano.

Os passeios em família e com amigos são importantes para o aumento na frequência de um museu como espaço para o lazer, corresponde um em cada cinco visitas. Outro aspecto são as pessoas que vão ao Te Papa para fazer compras, corresponde a $6 \%$ da visitação. Outro uso do espaço é o restaurante para jantar, representa 4\% dos visitantes (DAVIDSON; SIBLEY, 2011).

Uma característica também observada na relação dos museus com o lazer é que uma parcela significativa de visitantes é constituída por pessoas que possuem parentesco entre si. As famílias buscam os museus para o lazer objetivando com isso melhor interação entre os membros. Observa-se também a função educacional/informacional em um ambiente de museu quando, por exemplo, uma família realiza visita com a companhia de uma criança, pois muitas vezes os principais atrativos estão ligados a ludicidade (GARNER, 2015; DAVIDSON; SIBLEY, 2011).

A globalização não é um fenômeno atual, mas neste século vem sendo marcada por um avanço acelerado da tecnologia com transformações em processos de trabalho principalmente os associados a empresas transnacionais. A precarização e exploração intensa nos processos de trabalho são uma realidade, precarizando também o convívio em família. As pessoas neste século sentem necessidade de enraizamento, de utilizar seu 
tempo livre para modelar suas identidades pessoais e sociais. A família e grupos sociais são fundamentais para plasmar essa identidade (BRUMER, 2009; COSENTINO, 2013).

Os pais utilizam intencionalmente esse tempo de lazer com os filhos para alcançarem uma maior comunicação e coesão familiar, além de ensinar a seus filhos lições de escolhas de vida e moralidade (GARNER, 2015; MILLER, 2011), o que traz ao campo do lazer uma obrigatoriedade no mundo contemporâneo. Alguns pais narram o lazer no museu como uma oportunidade de aprendizado do filho, do valor educativo, das atividades oferecidas ser um recurso diferente de outras fontes como a escola, livros, televisão, pois o aprendizado é realizado na interação com os filhos e torna a experiência mais rica. De outro modo, há pais que lutaram por uma carreira acadêmica, não tiveram oportunidades na infância e vem o lazer no museu como um instrumento para oferecer aos filhos o que não tiveram e amenizar o caminho de suas carreiras profissionais (GARNER, 2015). Os sentidos e significados atribuídos pelos pais sobre o lazer com seus filhos em museus é tensionado pela questão da atividade produtiva na infância, quer dizer, o aprendizado escolar, como exemplo a implementação de bases fortes para a constituição de uma carreira. O lazer nesta perspectiva não é contraposição ao trabalho como preconizado por Dumazedier (1979).

Há museus que tem em seus objetivos essa relação do lazer familiar e a construção de identidades, criando eventos interativos entre os membros da família e/ou amigos (MILLER, 2011). Há estudos que quando perguntado as pessoas sobre o que fazer na cidade em seu tempo livre para o lazer, foi respondido que os museus são opções buscadas, especialmente com a companhia das crianças (LONGHURST; BAGNALL; SAVAGE, 2004, p. 110).

Em uma investigação na qual se observou o lazer das famílias nos museus, foi analisada a questão do envolvimento por gêneros masculino e feminino na interação dos 
visitantes familiares. A pesquisadora estava aberta a observar todos os tipos de famílias constituídas por gays, lésbicas, LGBT, pais divorciados, entre outros, mas essas características não foram evidenciadas, portanto, o estudo refletiu a história de famílias constituídas por pai, mãe e filhos. A questão do gênero entre o masculino e feminino ficam destacadas, no qual as mães focam na gestão de seus filhos enquanto os pais enfatizam o jogo. As mães não focalizam a brincadeira com os filhos, esses brincavam independentes ou acompanhadas do pai. As mães em geral ficavam sentadas nos bancos próximos, preocupadas com o paradeiro dos filhos a fim de que os mesmos não lhe saiam da vista, algumas mães inclusive colocam roupas com cores que facilitavam o rastreamento do filho. A figura paterna observada nos museus age com os filhos como pares, fazem brincadeiras, jogam sentados lado a lado com as crianças, conversam, riem, constroem juntos a diversão, raramente ficam no gerenciamento das crianças. Durante a pesquisa três pais perderam seus filhos dentro de museu e não foi visto isso ocorrer em relação às mães (GARNER, 2015). Outra pesquisa sobre visitantes em museus trouxe mais dados sobre a questão de gêneros de visitantes, quando revelou que as mulheres se apresentam mais frequentemente com a família nessas instituições. Contudo, essa mesma pesquisa aponta que o conteúdo temático das exposições influencia diretamente na decisão em ir ao museu, ou seja, há exposições que chamam mais atenção das mulheres do que dos homens e vice-versa (DAVIDSON; SIBLEY, 2011).

As relações familiares no ambiente de lazer continuam afirmando a construção social dos papeis femininos e masculinos na sociedade. No lazer continua a reprodução da dedicação feminina a vida familiar, a mãe fica administrando os cuidados com os filhos e as atividades de lazer no museu passam a ser a extensão do seu papel dedicado em casa. A diferenciação entre os gêneros continua a existir em espaços de lojas e 
lanchonetes do museu. A mãe incorpora a gestão do lanche, dos gastos, buscando colocar limites nas compras, enquanto os homens assim como as crianças aguardam o lanche sentados e compram brinquedos por acharem interessantes (GARNER, 2015). No entanto, é importante observar que estas diferenças não são algo da natureza do homem e da mulher, essa divisão de papel é algo construído socialmente em um processo histórico. O gênero é uma categoria social imposta por um corpo sexuado (SCOTT, 1995).

Ainda sobre as relações familiares no espaço do museu, encontramos dois estudos. O primeiro na Nova Zelândia relata que os pais se utilizam da ida em família ao museu como um momento que eles poderão recordar juntos no futuro (THYNE ${ }^{9}$, 2001 apud DAVIDSON; SIBLEY, 2011). O segundo, na Inglaterra, revelou que avós realizam visita com os netos a museus como opção educativa $\left(\right.$ BEAUMONT $^{10}$; STERRY, 2005 apud DAVIDSON; SIBLEY, 2011).

Outro aspecto do lazer na modernidade é associação do museu a um espaço de compensação de tensões e o controle das emoções, permitindo ao indivíduo a manifestação de suas emoções e a excitação. O lazer na contemporaneidade preza de alguma forma a exploração de emoções sem colocar em risco a vida social (RUGISKI; PILATTI, 2005). Os museus de arte são um destes lugares que as pessoas escolhem para passar o tempo livre. Em uma pesquisa com 100 adultos que visitaram o Kunsthistoriches Museum, em Viena, Áustria, consideraram o museu de arte como espaços para contemplação, para um lazer lúdico, educativo e que provocam expressões emocionais energizantes (ROBERSON, 2011).

\footnotetext{
9 THYNE, M. The importance of values research for nonprofit organisations: The motivation-based values of museum visitors. International Journal of Nonprofit and Voluntary Sector Marketing, n. 2, p. 116-130, 2001.

10 BEAUMONT, E. AND STERRY, P. A study of grandparents and grandchildren as visitors to museums and art galleries in the UK. Museums and Society, n.3, p. 167-180, 2005.
} 
A visita ao museu de arte é uma maneira que o visitante tem de aproximar da obra de arte e lidar com sentidos e sentimentos durante o percurso expositivo.

O olhar é um sentido descrito pelos visitantes como parte do desenvolvimento da sensibilidade. Cada visitante desenvolve esse sentido de uma maneira, aproximando e distanciando da obra, comparando uma com a outra, encontrando as qualidades da obra de arte e o que a mesma transmite. A obra de arte desenvolve o desejo de tocá-la, cheirá-la e isso leva a uma diminuição do stress para os visitantes. Então apreciar a obra de arte envolve a percepção, a sensibilidade, a emoção e essa relação da arte e os sentidos são considerados pelos visitantes como momentos de lazer (ROBERSON, 2011).

Há um projeto na Finlândia denominado companheiros da arte e cultura que é relacionado à ideia da arte socialmente comprometida. Diversas galerias e museus fazem parte desse programa. A ideia é incentivar as pessoas a desfrutar dessas instituições, inclusive com a inclusão de pessoas com deficiências e idosos, a fim de que as mesmas participem de eventos culturais, tornado a cultura mais acessível.

Os guias, que são pessoas voluntárias desse projeto, são amadores e tanto eles quanto os visitantes têm oportunidades de lazer, pois acompanham indivíduos e grupos para exposições (YANG, 2014).

Quando se tem essa proposta supracitada, na qual os museus se tornam um fórum criativo na participação da comunidade na arte e cultura, as pessoas que trabalham como voluntários exercem papel importante, na motivação desse tipo de lazer. Os voluntários têm sido motivação de estudos no campo do lazer. Esse estudo realizado na Finlândia traz a reflexão dos voluntários em museus exercerem a função com duplo sentido: o sentido de altruístas, pois proporcionam a aproximação das pessoas, inclusive populações como pessoa com deficiência e idosos no contato com a 
arte e cultura e a outra de fórum mais individual que é a satisfação das necessidades pessoais. Os voluntários consideram suas práticas como um lazer capaz de criar auto identidade, aprendizagem, oportunidade de socializar com as pessoas, estarem cercadas por interessantes coleções de museus e cultura, experiências que podem beneficiar sua futura carreira, além de proporcionar um sentimento de satisfação em servir a comunidade. Essa perspectiva do lazer é relacionada à capacidade que essa atividade voluntária tem em criar significado na vida dos voluntários, pois se auto realizam, auto enriquecem, auto expressam, estabelecem sentimentos de realização, de pertencimento, melhoram a autoimagem, interagem socialmente (YANG, 2014). O lazer de forma geral, e a participação em atividades culturais em particular, estão sendo usados como indicadores no aumento da qualidade de vida das pessoas.

Existem ainda poucos estudos que comparam os diferentes tipos de atividades de lazer, incluindo artes e cultura, como contribuição para a melhoria na qualidade de vida e também trabalhos na área de lazer sobre as experiências individuais dos visitantes dentro do museu (BROWN; MACDONALD; MITCHELL, 2015; ROBERSON, 2011). Essa situação ocorre em parte devido ao número restrito de atividades consideradas de lazer (BROWN; MACDONALD; MITCHELL, 2015). O conceito de satisfação que o indivíduo tem com a vida e outros termos relacionados, como a qualidade de vida e o bem-estar subjetivo, tem sido objeto de muitos debates em várias áreas. Uma alta satisfação com a vida foi associada ao engajamento em diferentes atividades de lazer ativo-criativas. Essa constatação surge quando se estabelece associações entre o tipo, número e frequência de participação em atividades de lazer (BROWN; MACDONALD; MITCHELL, 2015). Esse fato deve ser levado em consideração para elaboração de estratégias para construção de políticas públicas com vistas a melhoria da qualidade de vida através do lazer que promove a interação social (BROWN; MACDONALD; 
MITCHELL, 2015; ROBERSON, 2011). Equipamentos culturais como museus, teatros, galerias de arte e outros, fazem parte das opções de lazer ofertadas a população.

As pessoas vão a museus em geral em seus tempos livres e durante a experiência de visitar o museu, ocorrem interações com outros visitantes e amigos, sendo isso considerado uma prática de lazer (ROBERSON, 2011). Essa oportunidade de interação de participação em uma atividade socializante é um dos itens importantes para avaliação da qualidade de vida das pessoas. A Interação social em si tem sido reconhecida como um componente que contribui para o bem-estar das pessoas (BROWN; MACDONALD; MITCHELL, 2015).

Porém, o museu como categoria de lazer não tem resultado estatisticamente significativo para a melhoria na qualidade de vida, mas isso não significa necessariamente que eles não contribuem para o bem-estar (BROWN; MACDONALD; MITCHELL, 2015). Nesse sentido, o lazer é o tempo livre para perseguir atividades que são pessoalmente agradáveis e benéficas (ROBERSON, 2011). Há também explicações sobre a inserção em atividades de lazer serem motivadas por diversas recompensas: recompensas pessoais, sociais, contribuição para a comunidade, a possibilidade de gerar capital social, reconhecimento e confiabilidade (STEBBINS ${ }^{11}, 2004$ apud YANG, 2014).

O comportamento das pessoas quando buscam o lazer se diferem também pelo seu contexto (SCHALLER; HARVEY; ELSWEILER, 2012). Existem estilos de lazer, como por exemplo, o lazer esportivo, o cultural, o que envolve consumo e dentre outros há o lazer casual que busca um prazer passageiro e está sujeito a perder seu apelo e ficar em níveis baixos de satisfação em curto prazo (STEBBINS, 2004). As pessoas que

\footnotetext{
${ }^{11}$ STEBBINS, ROBERT A. "Introduction", in Volunteering as Leisure/Leisure as Volunteering: An International Assessment, edited by Robert A. Stebbins and Margaret Graham, Wallingford, Oxfordshire: CABI, 2004.
} 
buscam o lazer casual não se importam com o conteúdo da informação, estão preocupados com a resposta emocional e física (SCHALLER; HARVEY; ELSWEILER, 2012). Os museus e eventos veem adaptando a satisfação também desse lazer casual.

Em Monique, na Alemanha, há um evento anual, intitulado 'Longa noite dos museus", no mês de outubro, que abre por uma noite os museus, e dentre alguns desses museus, há atividades especiais. Em 2011 estima-se que 20.000 pessoas visitaram um total de 176 eventos em 91 locais distintos, incluindo exposições, galerias e eventos interativos.

Os eventos ocorrem em toda cidade. Os visitantes são moradores de Monique e turistas de várias faixas etárias e classes sociais. Foi desenvolvido um aplicativo para ajudar os visitantes a encontrarem eventos de seus interesses pessoais. O sistema tenta maximizar o número de eventos agendados entre outras possibilidades (SCHALLER; HARVEY; ELSWEILER, 2012).

Uma pesquisa avaliou a interação de 391 usuários com o aplicativo desenvolvido, a fim de compreender o comportamento de busca dos usuários. Anterior à pesquisa da interação com o aplicativo foi realizada entrevistas com 25 pessoas presentes no evento, poucos entrevistados relataram ter uma busca específica de eventos que gostariam de visitar. A maioria descreve necessidades de prazer, de terem uma noite agradável, com amigos, diversificar seus conhecimentos entre outros.

Há ausência de consultas, por exemplo, sobre teores específicos de eventos como história da arte, engenharia etc. Também não buscam novos eventos, mas eventos que já sabiam de sua existência (SCHALLER; HARVEY; ELSWEILER, 2012).

Nesta pesquisa então, trabalha-se a questão do uso do aplicativo como facilitador da busca de eventos culturais casuais em museus, a possibilidade de diversificação das 
visitas com busca mais amplas. No entanto se verifica que o aplicativo é utilizado para buscar eventos pré-determinados pelas pessoas e é abandonado brevemente. Um estudo mais aprofundado de sistemas de suporte para suprir necessidades de lazer casual, principalmente em eventos como esse que ocorre em Monique, poderá motivar as pessoas irem aos museus como uma opção de lazer.

A busca por museus como uma opção de lazer vem crescendo a cada dia. Por exemplo, cinco milhões de pessoas visitam anualmente o Metropolitan Museum of Art em Nova York. Pessoas viajam para Bilbau, Espanha, com o único propósito de visitarem o Museu Guggenheim, considerado um dos locais mais visitados no país, outros viajam para Paris, Kyoto, Dubai, Florença, Madrid, Roma para visitarem museus significativos naqueles lugares. A popularidade dos museus continua a aumentar (ROBERSON, 2011).

Essa popularidade dos museus vem se estendendo também a visitantes que utilizam a WEB em suas práticas de lazer. Em uma pesquisa no National Museum of Military History situado em Copenhague, na Dinamarca, que digitalizou suas coleções e deu acesso online a população, se constata que há um nível de conhecimento alto ou mediano dos visitantes sobre a temática, atingindo quase $88 \%$ destes. Os mesmos retratam suas visitas como um hobby, considerado por alguns autores uma categoria de lazer, que tem em sua natureza a aquisição de conhecimentos. São visitantes especiais, em geral colecionadores de armas militares, interessados nos períodos da primeira e segunda guerra mundiais, com amplo interesse em história militar e que buscam nas visitas ampliarem ainda mais seus conhecimentos (SKOV, 2013).

Uma característica dos participantes da pesquisa que utilizam as novas tecnologias sejam para visitar os museus ou como ferramenta para buscas culturais em 
lazeres casuais, é que todos buscam a partir de conhecimentos prévios. Não há uma busca aleatória, a busca por algo novo.

No caso especifico de lazer em museus temáticos nos quais os colecionadores são visitantes, estes focam na construção, desenvolvimento e manutenção de suas coleções particulares. Outra característica desse visitante é a partilha de informações, buscam também desenvolver competências sobre o tema para seu bem próprio (SKOV, 2013).

O espaço museológico como um possível local para se ter práticas de lazer, é algo presente na contemporaneidade e não é ainda um espaço democrático, no qual todas as camadas sociais participam. A classe média e média alta são as privilegiadas neste contexto. Esse fato tem relação com o estigma do museu como lugar de elite, como um espaço sacralizado, o que gera barreiras culturais (LACERDA; ISAYAMA, 2010).

Como observado em vários artigos, o aproveitamento do museu como espaço de lazer na atualidade está associado a utilização do tempo livre como extensão de trabalho (SOUSA, 2009) ou pelo menos relacionado a atividades produtivas. As pessoas vão a museus ou navegam neles para adquirir conhecimentos, para proporcionar acesso a cultura. O que estabelece diálogos com a ideia de lazer sério, quer dizer pessoas que buscam aquisição de conhecimento, entretenimento ligados a uma formação, uma auto realização profunda no campo da arte, da ciência, do esporte (STEBBINS, 2007). Neste aspecto de auto realização, destaca-se o trabalho de voluntários nas instituições museológicas. Outros tipos de lazer também são encontrados nos visitantes dos museus, que é o lazer como hobby, no qual as pessoas utilizam seu tempo livre para cultivarem hobbys e também o lazer casual que não requer nenhuma habilidade latente, nenhum 
treinamento especial para se divertir, é apenas vivenciado momentaneamente, tem curta duração, é associado ao puro prazer (STEBBINS, 1997).

As instituições museológicas na contemporaneidade exercem um papel importante no campo do lazer e faz-se necessário que essas instituições possam democratizar esse lazer, criar zonas de sentidos, aproximando das populações marginalizadas, trazendo um dialogo inclusivo, amplo, no qual todas as camadas sociais possam fazer parte.

\section{Marketing em Museus}

O mundo contemporâneo é caracterizado pelo acesso rápido a informação com o advento da internet. Em todos os setores da sociedade moderna o uso de meios tecnológicos como ferramental de promoção e marketing vem sendo largamente usado. Os grandes museus estão atentos a importância do marketing para melhorar a visitação, ou seja, atrair mais pessoas (ROBERSON, 2011).

Para ser competitivo no mercado de hoje, o museu deve olhar para o seu produto, fazer avaliações, e focar esforços de marketing sobre como os visitantes, e especialmente os não visitantes, precisam e querem gastar seu tempo de lazer. Um raro exemplo de um trabalho contínuo e permanente sobre isso é o que foi institucionalizado no Museu Te Papa Tongarewa, o mais visitado da Australásia, localizado na cidade de Wellington, Nova Zelândia. Alguns anos antes da inauguração da nova sede do museu, em 1998, foi realizada uma pesquisa, por meio de uma entrevista, onde foram arquivadas $81 \%$ das 753 (setecentos e cinquenta e três) realizadas com os visitantes. Esta entrevista teve o objetivo de investigar o impacto da transição do "velho museu" para o "novo museu" para seus visitantes (DAVIDSON; SIBLEY, 2011). Com os resultados foi possível também planejar os conceitos das novas exposições. Isso foi o 
ponto de partida para o trabalho de pesquisa existente até hoje no museu, que visa principalmente manter o Te Papa atualizado com dados sobre o perfil e as necessidades de seus visitantes, facilitando, entre outras ações, as de marketing (DAVIDSON; SIBLEY, 2011). Esclarecendo melhor o caso do Museu Te Papa, ele já existia desde 1992, porém, em 1998, sua concepção foi totalmente reformulada, tornou-se verdadeiramente um "novo" museu, não só em termos arquitetônicos, mas em seus atributos como instrumento de inclusão, importância e abrangência da comunidade onde está inserido. A arquitetura atrativa do novo prédio, somada a melhor localização e com objetivos focados em proporcionar lazer, fez com que o "novo" Te Papa ampliasse e aumentasse consideravelmente o número de visitantes em relação ao "velho" Te Papa que se configurava na tipologia de um museu nacional tradicional (DAVIDSON; SIBLEY, 2011).

Estudos recentes têm mostrado que hoje os museus enfrentam reduções de financiamento do governo, fundações privadas, patrocínios e de doadores. Os museus nos Estados Unidos e no mundo estão se concentrando em provar seu valor para o público e para as organizações de subvenção (MILLER, 2011).

Há um desafio significativo para os museus ao redor do mundo no século 21 , o de manter o volume de visitantes. O museu compete hoje com a expansão do mercado de lazer. Jovens adultos com maior nível de renda e nível educacional são os visitantes dos museus na atualidade (DAVIDSON; SIBLEY, 2011). Para mudar esse quadro, novas medidas de democratização com abertura do museu a grupos minoritários se fazem necessário e poderá gerar um processo de transformação social.

Para que os museus tenham ações efetivas é necessária a compreensão dos visitantes em relação a gênero, idade, nível educacional, etnia, lugar de origem, assim como as razões da visita, frequência e contexto e também os níveis de 
comprometimento com a proposta museológica para que ações mais efetivas e de alcance social diversificado sejam implementadas (DAVIDSON; SIBLEY, 2011).

Foi realizado um estudo no Museu de Arte Figge, em Davenport, Iowa, Estados Unidos no qual analisou os objetivos do museu em incluir o visitante em áreas de marketing do museu, a fim de que o mesmo sirva ao público e seja inclusivo. Abordou também a pesquisa de práticas construtivistas em estudos sobre museus, além de uma pesquisa de não visitantes identificando suas necessidades de lazer (MILLER, 2011).

Atualmente o financiamento público de museus está associado a resultados de desempenho de instituições mais eficientes. Os museus têm que ter dados quantitativos e de desempenho sobre número de visitantes, bilhetes vendidos e pesquisas de satisfação para que recebam investimentos. Tem-se exigido dos museus habilidades gerenciais para atrair mais visitantes e melhorar sua imagem, a fim de aumentar suas receitas a partir também de financiamento público, permitindo assim, a sobrevivência dos museus em períodos de restrições de gastos (AMENTA, 2010).

A pesquisa supracitada foi realizada em duas etapas: a primeira entrevistou três membros da equipe Figge de marketing, e investigou os métodos e abordagens utilizadas para tratar as necessidades dos visitantes e decisões de marketing. Além disso, verificou se há esforços do museu para aumentar o público através do levantamento das necessidades dos visitantes e não-visitantes em seu tempo livre para o lazer.

A segunda etapa da pesquisa utilizou a rede social Facebook por meio da SurveyMonkey com foco em não-visitantes do Museu Figge. Os não-visitantes foram questionados sobre as motivações e razões para seu tempo de lazer em usufruir de eventos esportivos, cinema e museu (MILLER, 2011). 
Houve várias implicações encontradas nas respostas dos membros da equipe Figge, uma delas é que as práticas de marketing são trabalhadas de forma inconsistente não compreendendo o processo de comercialização (MILLER, 2011). Essa relação entre marketing e museu gerou por muito tempo um desconforto, principalmente nos gestores, pois para eles trazia os museus para o campo do comércio que de certa forma poluía um local "santificado" com questões de consumo. No entanto, na atualidade o marketing ganhou importância na gestão cultural e artística (KOMARAC, 2014). É considerado um aspecto fundamental para sobrevivência dessa instituição. Museus atualmente fazem parte de um entretenimento e têm enfrentado a concorrência de novas tecnologias de museus virtuais, da realidade virtual, por isso a necessidade da utilização do marketing como ferramenta de sobrevivência, o que vem gerando desafios ao pensar os museus como negócio (KOMARAC, 2014). Analisar como o mercado-alvo está mudando, e focando na captação de novos públicos, deve estar na agenda do plano de marketing do museu (MILLER, 2011).

Especificamente, o Museu de Arte Figge busca colocar em prática o uso de abordagens inclusivas com seus visitantes. No Figge existe uma equipe de marketing com representantes de cada departamento, em vez de um setor centralizado. Cada um dos membros da equipe contribui com tempo e esforço para tomadas de decisões.

A avaliação de satisfação dos visitantes é uma tarefa importante para os museus, pois fornecem dados a serem trabalhados em estratégias de marketing com vistas no aumento do número de visitantes (MILLER, 2011). Com a mudança da disponibilidade de tempo de lazer, nos dias de hoje, a abordagem inclusiva exige que o marketing em museu concentre esforços sobre as necessidades do não visitante para aumento do número de visitantes e para alcançar os objetivos educacionais do museu. A motivação dos visitantes e não visitantes são uma chave de marketing para o aumento do fluxo de 
pessoas em museus. A pesquisa no Figge identificou a motivação do visitante para uso do museu como local de lazer e direcionou o marketing para 5 categorias de visitantes:

a) $\mathrm{O}$ explorador: visitante que necessita satisfazer o interesse geral e a curiosidade; b) $\mathrm{O}$ facilitador: visitante que deseja partilhar a experiência do museu com uma amigo ou familiar; c) O buscador: visitante que deseja uma experiência nova; d) Amado: Visitante cujo interesse está ligado ao trabalho ou em outras áreas da vida; e) Recarregador: Visitante que está interessado em relaxamento, introspecção ou rejuvenescimento (MILLER, 2011). Um forte motivador para o visitante ir ao museu tem relação com a rotatividade das exposições museológicas temporárias e da atualização das exposições de longa duração. Essas ações aumentam a reputação do museu e consequentemente a curiosidade das pessoas sobre o mesmo (DAVIDSON; SIBLEY, 2011).

Os museus têm estendido o estudo de comportamento do visitante online. $\mathrm{O}$ lazer online atualmente é uma realidade, portanto estudar as características desse visitante em relação as suas necessidades de informações, a sua busca e seu uso poderá contribuir para o desenvolvimento de sites atraentes, relevantes e úteis (SKOV, 2013) e assim, aumentar o potencial do marketing nos museus.

Mesmo que haja estudos de marketing com os visitantes, ainda é reconhecido a falta de foco nas necessidades dos visitantes, sugere-se que o marketing deva ser trabalhado no museu com vistas ao consumidor, identificando seus interesses, necessidades, percepções e motivações (MILLER, 2011).

No entanto, o consumo nos museus está associado a determinadas camadas sociais. Em uma investigação feita nos Estados Unidos, país que possui grande número de instituições museológicas, revelou que quanto maior a renda, classe social e 
educação do indivíduo, maiores são as suas intenções de visita a museus e galerias de arte $\left(\mathrm{MORI}^{12}, 2004\right.$ apud DAVIDSON; SIBLEY, 2011).

Vale trazer a reflexão de que o museu assim como diversas instituições inseridas no sistema capitalista está voltado também para o consumo. Hoje a inserção ao mundo do consumo é definida por um processo de desigualdade social. Os Marketings não consideram esse elemento, mas além da barreira sociocultural que pode afastar camadas menos favorecidas dos museus, muitas instituições museológicas têm custos para visita. Em geral esse é um aspecto que desencoraja as famílias de trabalhadores e pobres de irem ao museu. Nas instituições: Academy of Natural Sciences e Franklin Institute, cada entrada é em média 15 (quinze) dólares, além disso, muitas famílias têm que contar com custos de deslocamento (GARNER, 2015). No entanto, talvez essa seja uma meta inviável relacionar marketing com necessidades reais de lazer de populações marginalizadas, pois o mesmo é sustentado nos interesses de mercado.

\section{Considerações Finais}

Os museus vêm buscando adequar às novas exigências da indústria do lazer, o que tem repaginado as características dos mesmos na atualidade. Dentro da concepção da "Nova Museologia", percebemos que após o surgimento desse movimento, especialmente nas décadas entre 80 e 90, houve e ainda há contínua adaptação dos museus em processos de democratização de suas propostas. Configura-se uma relação com a indústria cultural do lazer em atrair mais "visitantes consumidores" ao museu como espaço de lazer. Motivam ofertas de atividades para um público diversificado tanto do ponto de vista socioeconômico como cultural.

\footnotetext{
12 MORI. Visitors to museums and galleries. Birmingham, UK: Council for Museums, Archives nd Libraries, 2004.
} 
Percebe-se ainda, que o museu enquanto instituição para vivências de práticas de lazer ainda não se configura como uma realidade para a comunidade. Não têm, portanto, cumprido uma das premissas do movimento da "Nova Museologia" do museu ser um sistema aberto e interativo em constante diálogo com a comunidade a fim de auxiliar o desenvolvimento da mesma (MENSCH ${ }^{13}, 1992$ apud XAVIER, 2012). Mas, também é importante pontuar, que a pesquisa focou na relação do lazer e museu, analisando artigos delimitados por estes dois descritores, o que pode ter limitado os achados sobre este tema. No entanto, os estudos trazem a experiência do lazer em museus especialmente por pessoas de nível econômico e sociocultural associado à classe média e média alta. Os museus maiores preocupam-se em ofertar lazer a seus visitantes, no entanto um lazer associado a uma elite, sem apontar projetos de inserção de visitantes de classes econômicas mais baixas e com menor aporte intelectual. Portanto, o uso do museu como local de lazer é realizado em grande parte por pessoas com nível elevado de educação. Há ainda uma parcela significativa da população que não têm o hábito de frequentar os museus sendo necessário um aprofundamento nos estudos sobre os não visitantes. Essa não frequência aos museus pode ter relações com valores e oportunidades para que haja maior inserção social de lazer nos museus.

Outro aspecto é que as famílias de classe média e média alta ao frequentarem os museus trazem para o espaço museológico a reprodução dos papéis femininos e masculinos construídos socialmente. A mulher dedicada à vida familiar, aos cuidados com filhos e marido, e o homem, ao espaço de diversão. Ou seja, o museu pode ser um espaço para pensar e transformar padrões de comportamentos e naturalizações dos papéis masculinos e femininos construídos históricos-culturalmente, produzindo outras formas de pensar e se relacionar com as questões de gêneros. O museu pode ser um

13 MENSCH, Peter Van. Modelos conceituais de museus e sua relação com o patrimônio natural e cultural. In: REUNIÃO ANUAL DO ICOFOM/LAM. I, 1992.Transcrição: Boletim ICOFOM/LAM, ano II, n. 4/5, ago. 1992. 
lazer que amplia saberes a partir de saberes pré-existentes. Outro aspecto de vivência do lazer nos museus são os aspectos emocionais que o mesmo proporciona. A exploração das emoções em momentos de lazer é algo que aparece em alguns artigos. Essa relação mereceria um maior aprofundamento, pois o lazer enquanto excitação, exploração de sensações e emoções é presente na sociedade atual que visa o consumo. Há tipologias de lazer mencionadas nos artigos e compreensão dos mesmos. Há associação do lazer em museus como um lugar que escolhem para passar o tempo livre e situações casuais.

No entanto, na atualidade esse tempo também tem sido mercantilizado. Os museus buscando entrar na sociedade de consumo, também voltam suas pesquisas para o mercado, inclusive quando propõem atrair pessoas para atividades casuais de lazer.

$\mathrm{Na}$ época em que vivemos, no qual a Nova Museologia e o uso do espaço museal como lazer vem dialogando com a indústria do lazer e com o consumo, observase o marketing nos museus como fator fundamental. Há uma tendência a profissionalização desta área do museu, no qual o trabalho seja realizado de forma eficiente, com pesquisas de perfil dos visitantes principalmente por instituições de renome. Essa ideia do Marketing em museus aliada aos interesses do mercado cria um cenário pouco convidativo as classes mais pobres da sociedade. Porém, ainda em números inexpressivos, começam a surgir museus com propostas identitárias especificas, são os chamados museus de território. Um exemplo dessa nova tipologia é o primeiro museu territorial e vivo sobre memórias e patrimônio cultural de favela do mundo, o MUF (Museu de Favela). Criado em 2008 e localizado na cidade do Rio de Janeiro e que abrange as comunidades do Pavão, Pavãozinho e Cantagalo. Onde seu principal acervo são seus milhares de moradores.

Percebe-se que o lazer em museus ainda não é utilizado como um processo de inclusão e democratização. As instituições museológicas na contemporaneidade têm 
potencial para exercerem um papel importante no campo do lazer, no entanto isso ainda

não ocorre de maneira significativa.

Constata-se ainda, com o estudo de produções acadêmicas, que a relação entre o lazer e os museus ainda é uma área em construção. O museu, instituição em constantes transformações ainda tem muito espaço para que seja explorado em termos de pesquisas científicas. Com relação a este trabalho observa-se que no âmbito internacional e especialmente no Brasil, a literatura que correlaciona os descritores museu e lazer ainda é escassa, merecendo maior investigação e produção científica.

\section{REFERÊNCIAS}

AMENTA, Carlo. Exploring Museum Marketing Performance: A Case Study from Italy. International Journal of Marketing Studies, v. 2, 2010.

BROWN, Jennifer L.; MACDONALD, Ronald; MITCHELL, Richard. Are People Who Participate in Cultural Activities More Satisfied with Life? Soc Indic Res, n. 122, p.135-146, 2015.

BRUMER, Anita. Gênero, família e globalização. Sociologias, Porto Alegre, n. 21, p. 14-23, jun. 2009.

CONAL, McCarthy. The rules of (Maori) art: Bourdieu's cultural sociology and Maori visitors in New Zealand museums. Journal of Sociology. June-September, v. 49 ,n. 2-3, p. 173-193, 2013.

CONSENTINO, Milena Callegari. A memória coletiva a construção de identidades em famílias da sociedade israelita. Dissertação (Mestrado), USP, Ribeirão Preto, 2013 .

COSTA, Heloisa Helena Fernandes Gonçalves da. Museologia e patrimônio nas cidades contemporâneas: uma tese sobre gestão de cidades sob a ótica da preservação da cultura e da memória. Bol. Mus. Para. Emílio Goeldi. Ciênc. Hum., Belém, v. 7, n. 1, p. 87 101, Apr. 2012.

DAVIDSON, Lee; SIBLEY, Pamela. Audiences at the "New" Museum: Visitor Commitment, Diversity and Leisure at the Museum of New Zealand Te Papa Tongarewa, Visitor Studies, 14:2, 176-194, 2011.

DUARTE, Alice. Nova Museologia os pontapés de saída de uma abordagem ainda inovadora. Revista Eletrônica do Programa de Pós-Graduação em Museologia e Patrimônio - PPG - PMUS Unirio MAST. v. 6 n.1, 2013. 
DUMAZEDIER, J. Sociologia Empírica do Lazer. Tradução de Silvia Mazza e J. Guinsburg. São Paulo: Perspectiva/SESC, 1979.

GARNER, Betsie. Mundane Mommies and Doting Daddies: Gendered Parenting and Family Museum Visits. Qual Sociol., n. 38, p.327-348, 2015.

GOMES, Christianne. Mapeamento Histórico do Lazer na América Latina: Em busca de novas abordagens para os estudos sobre o tema. In: ISAYAMA, Hélder Ferreira; SILVA, Sílvio Ricardo da (Org.). Estudos do lazer: um panorama. Rio de Janeiro: Apicuri, p. 145-164, 2011.

HOOD, M. "Staying away: Why people choose not to visit museums". In: Reinventing the museum: Historical and contemporary perspectives on the paradigm shift. Walnut Creek, CA: AltaMira Press, 2004. 150-157.

KOMARAC, Tanja. A new world for museum marketing? Facing the old dilemmas while challenging new market opportunities. Tržište, v. 26, n.. 2, p. 199 - 214, 2014.

LACERDA, Leonardo L. L., ISAYAMA, Hélder F. Marketing de serviços de lazer: estudo de caso do museu de artes e ofícios de Belo Horizonte. PASOS. Revista de Turismo y Patrimonio Cultural, v. 8, n. 4, 2010.

LONGHURST, B., BAGNALL, G. SAVAGE, M. Audiences, museums and the English middle class. Museums and Society, v. 2, n. 2, p. 104-124, 2004.

MENSCH, Peter Van. Modelos conceituais de museus e sua relação com o patrimônio natural e cultural. In: REUNIÃO ANUAL DO ICOFOM/LAM. I, 1992.Transcrição: Boletim ICOFOM/LAM, ano II, n. 4/5, ago. 1992.

MILLER, Kathleen J. Inclusive Marketing in the Constructivist Museum: A Study of Non-visitors' Needs. The International Journal of the Inclusive Museum, v.1. 3, n. 4, 2011. Disponível em: http://museum-journal.com/ Acesso em: 10 agosto 2015.

MORI. Visitors to museums and galleries. Birmingham, UK: Council for Museums, Archives nd Libraries, 2004.

NASCIMENTO, Rosana. A instituição museu: a historicidade de sua dimensão pedagógica a partir de uma visão crítica da instituição. Cadernos de Sociomuseologia, v. 11, n. 11, 1998.

ROBERSON, Donald N., Jr. Free Time in an art museum: pausing, gazin and interacting. 2011.

RUGISKI, M.; PILATTI, L. A. Lazer e tempo livre: um olhar sobre a teoria elisiana. In: SIMPÓSIO INTERNACIONAL PROCESSO CIVILIZADOR, 9, 2005, Ponta Grossa., Anais... p. 1-8, 2005.

SCHALLER, Richard; HARVEY, Morgan; ELSWEILER, David. Out and About on Museums Night: Investigating Mobile Search Behaviour for Leisure Events. Presented at Searching4Fun workshop at ECIR, 2012. 
SCOTT, J. Gênero: uma categoria útil de análise histórica. Educação \& Realidade, v. 20, n. 2, p. 71-99, 1995.

SKOV, Mette. Hobby-related information-seeking behaviour of highly dedicated online museum visitors. Information Research, v. 18, n. 4, December, 2013.

SMITH, L. Uses of heritage. London, UK and New York, NY: Routledge, 2006.

SOUSA, Cleide A.G. Espaços de arte como espaço de lazer: um estudo comparativo entre ações educativas do Museu Mineiro e Museu de Arte da Pampulha - Belo Horizonte. Dissertação de Mestrado, UFMG, Belo Horizonte, 2009.

SOARES, Bruno C. Brulon. Quando o museu abre portas e janelas: o reencontro com o humano no museu contemporâneo. 2008. 163 f. Dissertação (Mestrado em Museologia e Patrimônio) - Universidade Federal do Estado do Rio de Janeiro UNIRIO / Museu de Astronomia e Ciências Afins - MAST, Rio de Janeiro, 2008.

STEBBINS, ROBERT A. "Introduction", in Volunteering as Leisure/Leisure as Volunteering: An International Assessment, edited by Robert A. Stebbins and Margaret Graham, Wallingford, Oxfordshire: CABI, 2004.

$\frac{\text { Serious leisure: A perspective for our time. New Brunswick, NJ: Transaction, }}{2007}$. Casual leisure: A conceptual statement. Leisure Studies, v. 16, n. 1, p. 17-25,
$\frac{1997 .}{\text {. }}$,

THYNE, M. The importance of values research for nonprofit organisations: The motivation-based values of museum visitors. International Journal of Nonprofit and Voluntary Sector Marketing, n. 2, p. 116-130, 2001.

VARINE, Hugues de. As Raízes do Futuro: o patrimônio a serviço do desenvolvimento local. Porto Alegre: Medianiz, 2012. 256 p.

XAVIER, Denise Walter. Museus em movimento: uma reflexão acerca de experiências museológicas itinerantes no marco da nova museologia. Dissertação. Curso de Mestrado em Museologia, Universidade Lusófona de Humanidades e Tecnologias, Lisboa, 2012.

YANG, Jing. The Art and Culture Companions: Art Museum Volunteering as Serious Leisure in Finland. The International Journal of the Inclusive Museum, v. 7, 2014. Disponível em: www.onmuseums.com Acesso em: 13 agosto 2015.

\section{Endereço dos Autores:}

Evaldo Pereira Portela

Rua Odette de Oliveira Lacourt, 890. Apto 302 - Jardim da Penha

Vitória - ES - 29.060-050 
Cristiane Miryam D. de Brito e

Claudia Franco Monteiro

Endereço Eletrônico: evaldoportela@gmail.com

Cristiane Miryam Drumond de Brito

EEFFTO/UFMG

Av. Antônio Carlos 6627 - Pampulha

Belo Horizonte - MG - 31270-901

Endereço Eletrônico: cdrumonddebrito@gmail.com

Claudia Franco Monteiro

EEFFTO/UFMG

Av. Antônio Carlos 6627 - Pampulha

Belo Horizonte - MG - 31270-901

Endereço Eletrônico: caumont02@gmail.com 